\title{
Размерно-зависимые оптические свойства коллоидных квантовых точек CdS, пассивированных тиогликолевой кислотой
}

\author{
(C) Т.С. Кондратенко ${ }^{1}$, М.С. Смирнов ${ }^{1, \uparrow}$, О.В. Овчинников ${ }^{1}$, Е.В. Шабуня-Клячковская ${ }^{2}$, \\ А.С. Мацукович ${ }^{2}$, А.И. Звягин ${ }^{1}$, Я.А. Винокур ${ }^{1}$ \\ ${ }^{1}$ Воронежский государственный университет, \\ 394018 Воронеж, Россия \\ ${ }^{2}$ Институт фризики им. Б.И. Степанова Национальной академии наук Беларуси, \\ 220072 Минск, Республика Беларусь \\ ฯE-mail: smirnov_m_s@mail.ru
}

(Получена 15 сентября 2017 г. Принята к печати 18 октября 2017 г.)

\begin{abstract}
Представлены результаты исследования оптических свойств ансамблей коллоидных квантовых точек CdS, пассивированных тиогликолевой кислотой, со средними размерами от 1.7 до 5.8 нм. Методами рентгеновской дифрактометрии и спектроскопии комбинационного рассеяния установлено, что квантовые точки кристаллизуются в кубической кристаллической решетке. Установлены закономерности размерного эффекта в спектрах оптического поглощения и люминесценции, а также в спектрах возбуждения люминесценции, проявляющиеся в синем смещении соответствующих полос с уменьшением размера квантовых точек. На основе анализа наносекундной кинетики люминесценции сделали вывод о донорно-акцепторном механизме наблюдаемой излучательной рекомбинации.
\end{abstract}

DOI: 10.21883/FTP.2018.09.46149.8728

\section{1. Введение}

Полупроводниковые коллоидные квантовые точки (КТ) обладают особыми люминесцентными и абсорбционными свойствами, имеющими важное значение для большинства приложений нанофотоники [1-5]. Фотолюминесценция КТ, наряду с довольно высоким выходом и стабильностью характеристик во времени, имеет размерно-зависимые параметры соответствующих спектральных полос. При этом характеристики фотолюминесценции в значительной степени определяются избранным подходом к синтезу КТ $[1,4,6,7]$. Так, в рамках высокотемпературного металлоорганического синтеза с применением высокотоксичного компонента триоктилфосфиноксид (ТОРО) в качестве растворителя формируются коллоидные КТ, проявляющие преимущественно экситонную люминесценцию $[1-3,8]$. Полосы экситонного свечения отличает высокая интенсивность и селективность, а также малый стоксов сдвиг. Природу стоксового сдвига связывают с расщеплением экситона на „светлое“ и „темное“ состояния $[9,10]$.

Наряду с экситонной люминесценцией, как правило, наблюдают широкую бесструктурную полосу люминесценции, возникающей вследствие излучательной рекомбинации на уровнях структурно-примесных дефектов в КТ [4-8,11-25]. Высокотемпературные условия синтеза обеспечивают эффективную диффузию дефектов к границам КТ и заметное снижение интенсивности рекомбинационной люминесценции $[4-8,11,13,14]$. Наибольшего снижения интенсивности рекомбинационного свечения достигают пассивацией КТ (ядра) органическими комплексообразователями и оболочками из более широкозонных полупроводников (системы ,ядро-оболочка“) $[11,26,27]$. В системах „ядро-оболочка“ достижи- мы высокие характеристики ансамблей КТ, такие как монодисперсность и квантовый выход люминесценции порядка 70-90\% [27].

Альтернативные подходы к синтезу коллоидных КТ реализуют преимущественно в водной среде путем их стабилизации различными соединениями, содержащими активные к взаимодействию с поверхностью КТ группами, например, тиолами. Водород в SH-группе, как правило, замещается на ион металла, расположенный на поверхности КТ. Одним из используемых подобных стабилизаторов является тиогликолевая кислота (TGA) $[28,29]$. Такой подход обеспечивает гидрофильность и изменение люминесценции. Усиливается полоса рекомбинационной люминесценции наряду с полным тушением экситонного свечения.

Коллоидные KT $\mathrm{CdS}$ в отличие от КT CdSe и CdTe независимо от методики синтеза обладают преимущественно рекомбинационной люминесценцией. Ее квантовый выход удается увеличить до 70\% при оптимизации условий синтеза [7]. Механизмы излучательной рекомбинации рассматривают в рамках разнообразных моделей $[4,12,13,15-17]$. Обоснование соответствующей модели механизма люминесценции необходимо делать в каждом конкретном случае. При этом требуется однозначное понимание механизма размерного эффекта для наблюдаемой полосы люминесценции.

Настоящая работа восполняет имеющиеся пробелы в данной области и посвящена исследованиям размерного эффекта в оптических свойствах гидрофильных коллоидных КТ CdS, пассивированных TGA (KT CdS/TGA), со средним размером 1.7-5.8 нм. С использованием известных модельных представлений выполнен анализ механизма рекомбинационной люминесценции исследуемых образцов. 


\section{2. Методика исследования и образцы}

Синтез коллоидных КT CdS/TGA осуществляли в воде по методике, аналогичной [28,29]. Для синтеза использовали раствор прекурсора $\mathrm{Cd}^{2+} / \mathrm{TGA}$, полученный смешиванием $\mathrm{CdBr}_{2} \times 4 \mathrm{H}_{2} \mathrm{O}$ (448 мг, 1.3 ммоль) и TGA (240 мг, 2.6 ммоль). Бромид кадмия растворяли в воде (200 мл) и добавляли тиогликолевую кислоту. Далее в стакан каплями добавляли $\mathrm{NaOH}(1 \mathrm{M})$ и $\mathrm{pH}$ раствора доводили до 7. В приготовленный раствор $\mathrm{Cd}^{2+} /$ TGA быстро добавляли 50 мл водного раствора $\mathrm{Na}_{2} \mathrm{~S}$ (1.3 ммоль). Далее смесь нагревали до $95^{\circ} \mathrm{C}$ и выдерживали в течение 180 мин. Раствор постепенно приобретал светло-желтый цвет, что говорило о формировании KT CdS, пассивированных TGA. Пробы из стакана отбирали с течением времени. Синтезированные таким образом КТ CdS охлаждали до $25^{\circ} \mathrm{C}$ и добавляли этанол до $50 \%$ раствора, центрифугировали и повторно растворяли в бидистиллированной воде. Процедуру очистки повторяли несколько раз.

Структурные исследования выполняли методом просвечивающей электронной мироскопии (ПЭМ/ТЕМ), рентгеновской дифрактометрии и спектроскопии комбинационного рассеяния. Микрофотографии КТ получены на просвечивающем электронном микроскопе LEO 912 AB OMEGA (CarlZeiss, Германия). Рентгеновскую дифракцию (XRD) исследовали с помощью ARL X'TRA diffractometer (Швейцария) для $\mathrm{Cu} K_{\alpha}$-излучения.

Для исследований комбинационного рассеяния водный раствор КТ наносили на плазмонные пленки сереб$\mathrm{pa}$, сформированные на стеклянной подложке. Пленки высушивали в горизонтальном положении при комнатной температуре. Наночастицы серебра получали по методике восстановления нитрата серебра цитратом натрия. Кратко: 0.25 мл $0.2 \mathrm{M} \mathrm{AgNO} 3$ добавляли к 50 мл дистиллированной воды, раствор доводили до кипения, затем при постоянном перемешивании к нему добавляли 1 мл 1\%-го водного раствора цитрата натрия $\mathrm{Na}_{3} \mathrm{C}_{6} \mathrm{H}_{5} \mathrm{O}_{7}$. Реакционную смесь выдерживали при кипении 60 мин, затем охлаждали. Цитрат натрия является и восстановителем, и стабилизатором. Для иммобилизации наночастиц серебра на поверхности стекла применялся метод послойного электростатического осаждения. В качестве поликатиона использовали полидиаллидиметиламмоний хлорид (ПДАДМАХ), 200000 г/моль, Aldrich. Стеклянные подложки предварительно промывали в смеси $\mathrm{H}_{2} \mathrm{O}+\mathrm{H}_{2} \mathrm{O}_{2}+\mathrm{NH}_{3}(1: 1: 1)$ при $70^{\circ} \mathrm{C}$, затем на них осаждали слой поликатиона при обработке в растворе ПДАДМАХ в течение 20 мин. После промывки в воде подложки погружали в золь на 24 ч.

Полученные пленки исследованы методами сканирующей электронной микроскопии (SEM) с помощью TEM/SEM-микроскопа S-806 (Hitachi, Япония). Пленки представляли собой сплошной слой плотноупакованных наночастиц сферической формы.

Спектры комбинационного (КР) и гигантского комбинационного (ГКР) рассеяния регистрировали по схеме обратного рассеяния с помощью спектрометра Nanoflex (Solar LS, Беларусь), оснащенного аргоновым лазером, излучающим на длине волны 488 нм (мощность $0.2 \mathrm{MBT}$ ), а также дифракционной решеткой 1200 штрихов/мм.

Исследование поглощения и люминесцентных свойств осуществляли с использованием спектрометра USB2000+ (Ocean optics) с источником непрерывного излучения USB-DT (Ocean optics). Для возбуждения люминесценции использовали линию ртути 313 нм, выделяемую монохроматором МДР-41. Спектры возбуждения люминесценции КТ измеряли на автоматическом спектрофлуориметре, созданном на базе дифракционных монохроматоров МДР-4 и МДР-41, ксеноновой лампы 150 Вт в качестве источника. Регистрацию люминесценции и сбор данных осуществляли с помощью ФЭУ R928P (Hamamatsu, Japan), работающего в режиме счета фотонов, и блока сопряжения с компьютером.

Для исследования время-разрешенной люминесценции образцы возбуждали излучением полупроводникового лазера PLDD-250 (Alphalas) с длиной волны 375 нм при длительности импульсов 60 пс. Регистрировали излучение модулем ФЭУ PMC-100-20 (Becker \& Hickl $\mathrm{GmbH}$ ) и платы время-коррелированного однофотонного счета TimeHarp 260 (PicoQuant). Временно́е разрешение данной конфигурации аппаратуры составляло 0.2 нс.

\section{3. Результаты и их обсуждение}

\section{1. Рентгеновская дифракция и просвечивающая электронная мироскопия}

На рис. 1 представлены данные рентгеновской дифракции для коллоидных КT CdS/TGA. Все рефлексы оказались сильно уширенными из-за малых размеров кристаллитов. Положение обнаруженных рефлексов позволяет заключить, что нанокристаллы сформированы в кубической решетке (симметрия $F \overline{4} 3 m$ ). Проведенные оценки по формуле Дебая-Шеррера показали, что размеры КТ лежат в диапазоне от 2.0 до 5.5 нм. Этот результат коррелирует с полученными нами ранее данными для КТ $\mathrm{CdS}$ в желатине [30-34].

Микрофотографии, полученные методом ПЭМ, и гистограммы распределения по размерам для КT $\mathrm{CdS}$ двух средних размеров (2.3 и 4.5 нм) представлены на рис. $1, b, c)$. Видно, что синтезированные КТ представляют собой отдельные нанокристаллы с распределением по размерам около \pm 0.5 нм. Для остальных размеров КТ изображения аналогичны.

\section{2. Комбинационное рассеяние}

На рис. 2 представлены результаты исследования КР и ГКР для коллоидных КT CdS/TGA. Видно, что нанесение КТ на плазмонные пленки наночастиц серебра значительно усиливает интенсивность КР (рис. 2). Полученные спектры ГКР характеризуются интенсивной 

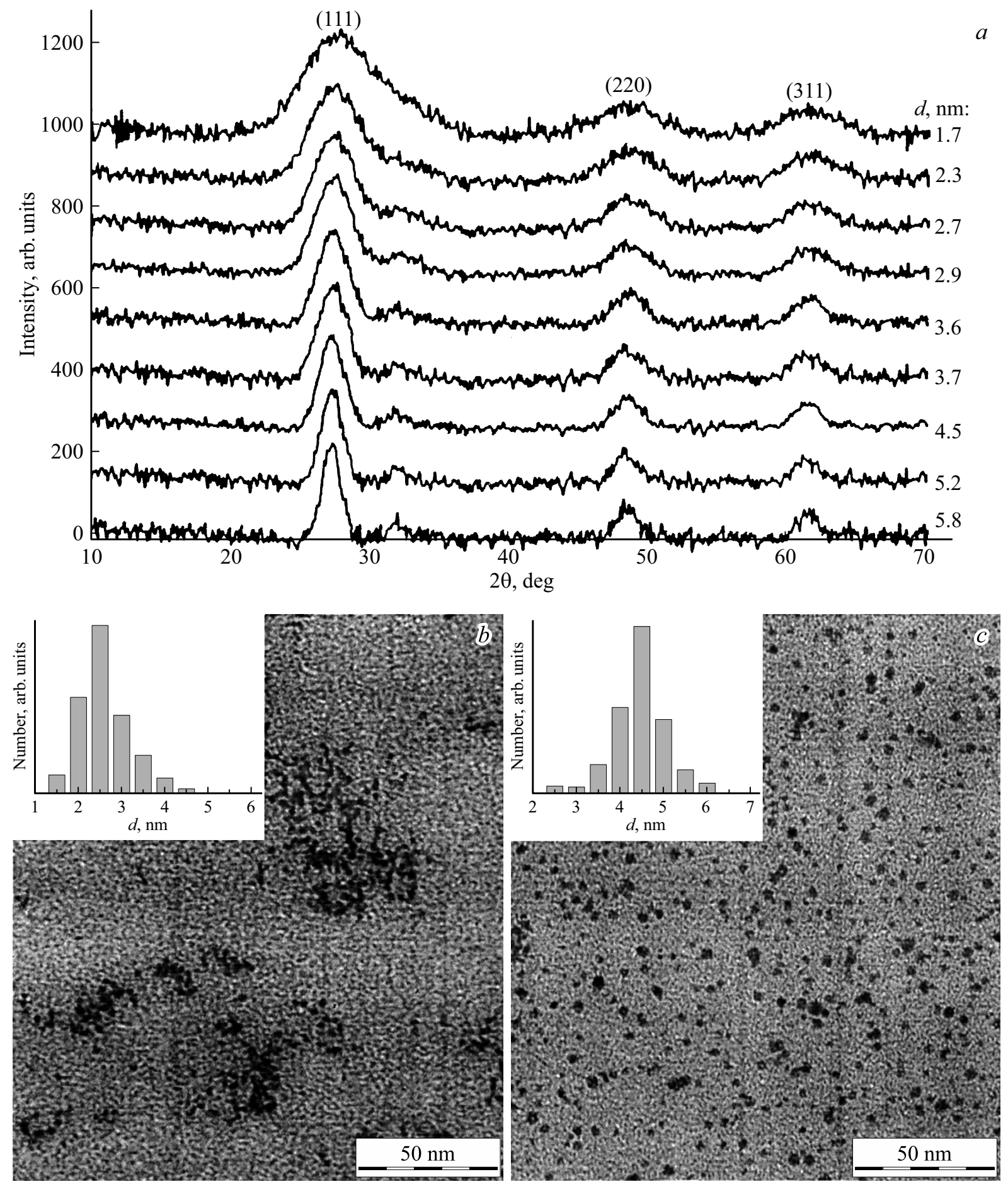

Рис. 1. Рентгеновские дифрактограммы для коллоидных КT CdS/TGA с различными средними размерами (a), ПЭМмикрофотографии и гистограммы распределения КТ со средними размерами $2.3(\bar{b}), 4.5$ нм (c).

полосой в области $298 \mathrm{~cm}^{-1}$. Данная полоса обусловлена проявлением в спектрах продольных оптических (LO) фононов, локализованных в KT CdS [35]. Полученные результаты подтверждают результаты работы [35], в которой сообщается об усилении комбинационного рассеяния света КТ в 40 раз при нанесении наночастиц серебра поверх образцов, а также данные авторов [36],

\section{.}




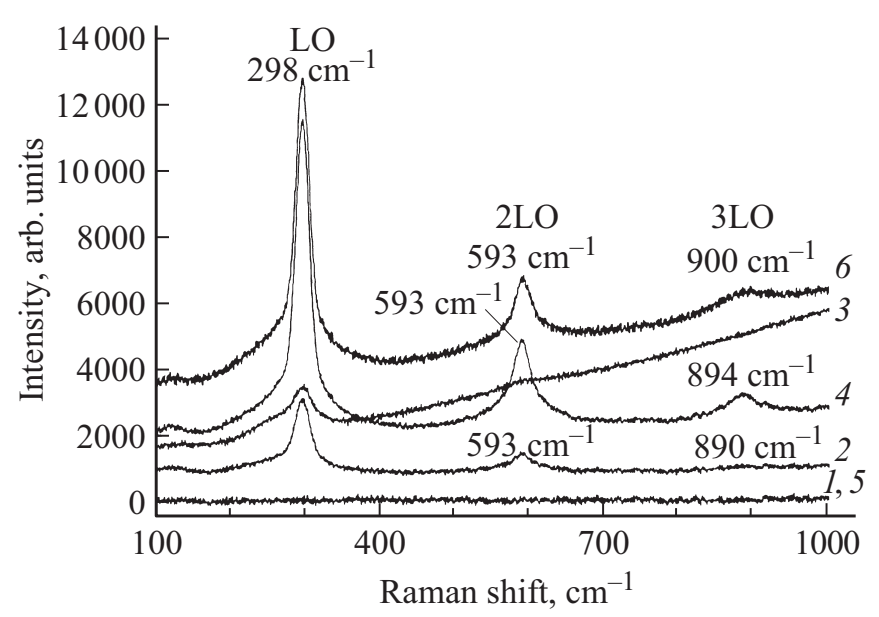

Рис. 2. Спектры КР $(1,3,5)$ и ГКР $(2,4,6)$ коллоидных KT CdS/TGA со средними размерами $2.7(1,2), 3.8(3,4)$, $4.5 \mathrm{Hм}(5,6)$.

и $894 \mathrm{~cm}^{-1}$ соответственно). Следует отметить, что при использовании плазмонных пленок серебра в качестве ГКР-активной подложки интенсивность полосы LO фононов в области $294 \mathrm{~cm}^{-1}$ достигает $\sim 3000$ отн. ед., в то время как на стекле спектры КР КТ CdS/TGA в данной концентрации зарегистрировать не удалось (рис. 2, кривые 1,5 ). Таким образом, можно говорить об усилении KР света KT CdS/TGA на 3 порядка. Наличие КР и ГКР для коллоидных КT CdS/TGA является свидетельством их упорядоченной кристаллической структуры, что подтверждает результаты XRD-исследований.

При увеличении среднего размера КТ от 2.7 до $3.8-4.5$ нм в спектре ГКР наблюдается усиление полосы на частоте $298 \mathrm{~cm}^{-1}$ не менее чем в 10 раз. Кроме того, в спектре ГКР проявляются полосы на частотах 593 и $890-900 \mathrm{~cm}^{-1}$, в то время как в спектре КР наблюдается преимущественно пик при $298 \mathrm{~cm}^{-1}$.

\section{3. Размерный эффект в оптическом поглощении и люминесценции коллоидных квантовых точек CdS/TGA}

Спектры оптического поглощения исследуемых образцов представляли собой широкие полосы, характерные для полупроводниковых КТ, с особенностью в области от 2.73 до $3.79( \pm 0.01)$ эВ (рис. 3), обусловленной наиболее вероятными оптическими переходами. Для образцов с наименьшими KT CdS/TGA соответствующая полоса имеет максимум. По мере выдерживания раствора КТ $\mathrm{CdS} / \mathrm{TGA}$ при $95^{\circ} \mathrm{C}$ полоса, соответствующая экситонному поглощению, испытывает длинноволновое смещение и становится слабо разрешенной.

Определение положения особенностей осуществляли по минимуму второй производной спектра поглощения по энергии кванта. Соответствующие значения энергии наиболее вероятного оптического перехода использо- вали в дальнейшем для определения размера КТ по эмпирической формуле X. Peng [37].

При возбуждении ультрафиолетовым излучением линии ртути с длиной волны 313 нм растворы коллоидных KT CdS/TGA проявляли интенсивную люминесценцию от сине-зеленой (размер КТ $d=1.7$ нм, длина волны $\lambda=490$ нм) до красной и инфракрасной области спектра $(d=5.8$ нм, $\lambda=710$ нм). Полосы люминесценции приведены на вставке к рис. 4. На основном же рисунке даны размерные зависимости энергии экситонного перехода в поглощении и максимума полосы люминесценции.

Для всех растворов коллоидных KT CdS/TGA полуширина полосы люминесценции была $>0.5$ эВ. При этом максимум полосы люминесценции сдвинут в длинновол-



Рис. 3. Спектры оптического поглощения коллоидных растворов КТ CdS/TGA со средними размерами $d=1.7,2.25,2.7,2.9$, $3.6,3.7,4.5,5.2,5.8$ нм.



Рис. 4. Размерная зависимость энергии экситонного перехода в поглощении, максимума полосы люминесценции для коллоидных КT CdS/TGA. На вставке - спектры люминесценции коллоидных KT CdS/TGA. 
новую сторону относительно полосы экситонного поглощения на величину, несколько превышающую $\sim 1.0$ эВ (рис. 4, кривые 1 и 2). При уменьшении размера KT CdS/TGA до 1.7 нм стоксов сдвиг увеличивался до 1.25 эВ. Значительный стоксов сдвиг позволяет отнести наблюдаемую люминесценцию к излучательной рекомбинации на уровнях структурно-примесных дефектов. Полосы люминесценции, так же как и спектры оптического поглощения, испытывали коротковолновое смещение при уменьшении размера КT CdS/TGA. Эта закономерность - также проявление размерного эффекта, но уже в люминесценции.

Аналогичные значения величины стоксова сдвига для рекомбинационной полосы люминесценции КТ CdS были обнаружены в ряде исследований [13,18-25,38].

\section{4. Спектры возбуждения люминесценции коллоидных квантовоых точек CdS/TGA}

На рис. 5 представлены спектры возбуждения люминесценции в рекомбинационной полосе коллоидных КТ $\mathrm{CdS} / \mathrm{TGA}$ со средним размером 2.9 нм в зависимости от длины волны регистрируемой люминесценции. Для всех спектров возбуждения характерно наличие хорошо разрешенной полосы. Ее максимум располагался в области 3.35 эВ для длины волны регистрируемого излучения 500 нм и смещался к 3.15 эВ для длины волны регистрируемого излучения 845 нм (красный край полосы люминесценции). Сравнение положения этой полосы с положением полосы в спектре поглощения этого же образца (рис. 5, кривая 10) позволяет отнести ее к основному наиболее вероятному переходу в оптическом поглощении КТ. Особенностью спектров возбуждения является более четкая структура наблюдаемых полос. Для наших образцов КT CdS/TGA при сканировании энергии кванта рекомбинационной полосы люминесценции в пределах в 1 эВ пик в спектре возбуждения смещается всего на 0.2 эВ. Для экситонной люминесценции благодаря жесткой связи между поглощением квантовыми точками одного размера и их испусканием при изменении длины волны регистрации свечения характерно такое же смещение пика в спектре возбуждения. Причина такого различия будет обсуждаться далее.

\section{5. Кинетика затухания люминесценции коллоидных квантовых точек CdS/TGA}

Затухание люминесценции KT CdS/TGA наблюдали во временно́м диапазоне $3 \cdot 10^{-1}-4 \cdot 10^{3}$ нс. Важно заметить, что в рамках методики время-коррелированного однофотонного счета интенсивность возбуждения крайне низкая. Таким образом, вероятность возбуждения биэкситона пренебрежимо мала и затухание люминесценции имеет для одной КТ простой закон, а измеренная кривая будет суммой по всем КТ в образце.

На рис. 6 представлено затухание люминесценции КТ $\mathrm{CdS} / \mathrm{TGA}$ диаметром 2.9 нм в полосе люминесценции

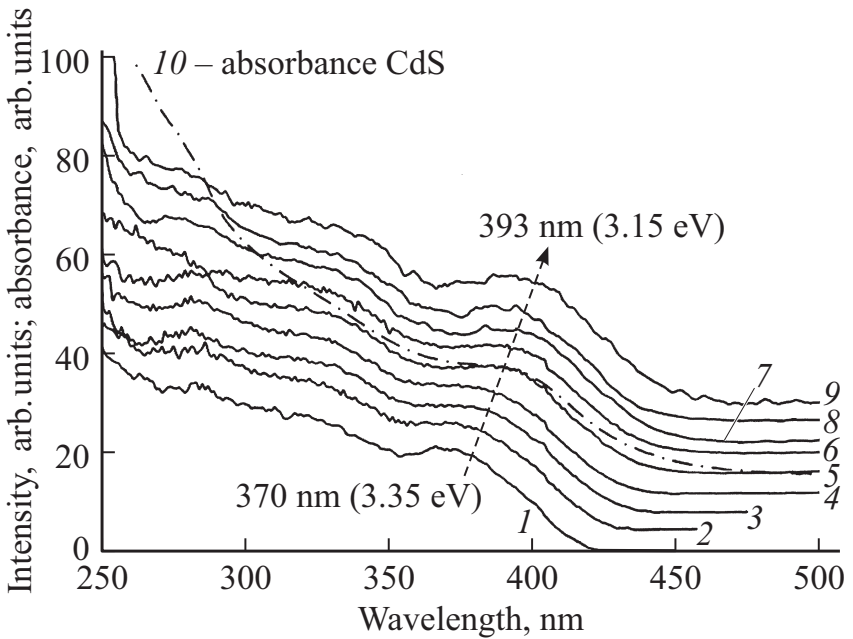

Рис. 5. Спектры возбуждения коллоидных КT CdS/TGA со средним размером 2.9 нм. Длина волны (энергия) регистрации люминесценции: $1-500$ нм $(2.47$ эВ), $2-530$ нм $(2.345$ эВ), $3-560 \mathrm{Hм}(2.22$ эВ), $4-595 \mathrm{Hм}(2.095$ эВ), $5-630 \mathrm{Hм}$ $(1.97$ эВ), $6-670 \mathrm{Hм}(1.845$ эВ $), \quad 7-720$ нм $(1.72$ эВ $)$, $8-775$ нм $(1.595$ эВ), $9-845$ нм $(1.47$ эВ). Стрелкой показан сдвиг максимума полосы. 10 - поглощение $\mathrm{CdS}$.

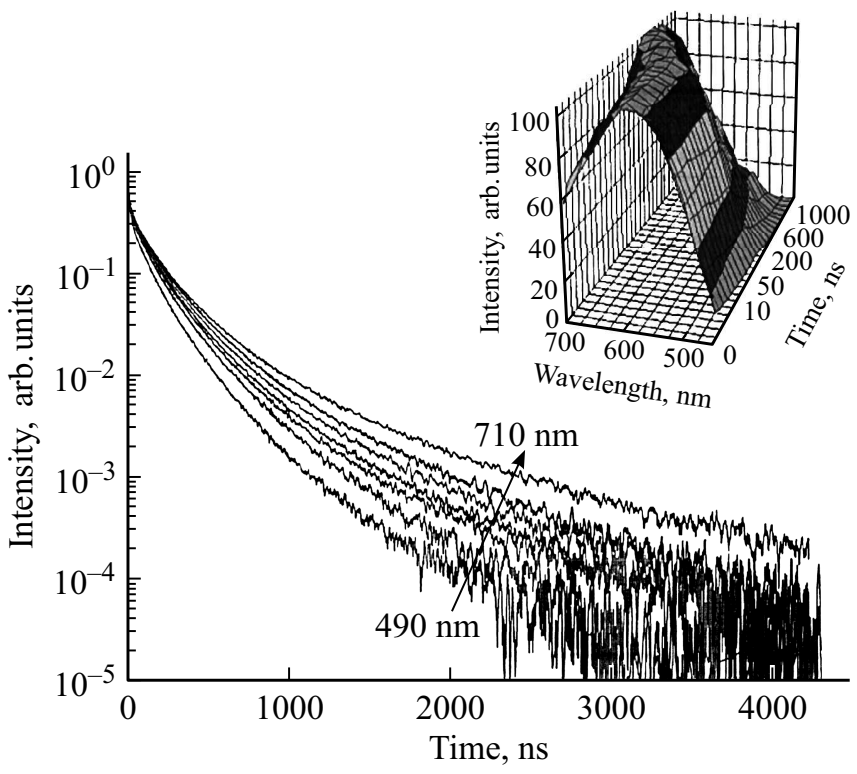

Рис. 6. Кинетика затухания люминесценции при сканировании в пределах полосы рекомбинационной люминесценции 490-710 нм в коллоидных КT CdS/TGA со средним размером 2.7 нм. На вставке - динамика мгновенного спектра свечения.

с максимумом при 2.1 эВ в зависимости от длины волны регистрации люминесценции. Все кривые затухания люминесценции описываются сложным мультиэкспоненциальным законом затухания. Неэкспоненциальный закон распада указывает на то, что структура квантовых переходов в КT CdS/TGA является сложной. Аналогичным образом неэкспоненциальный закон распа- 


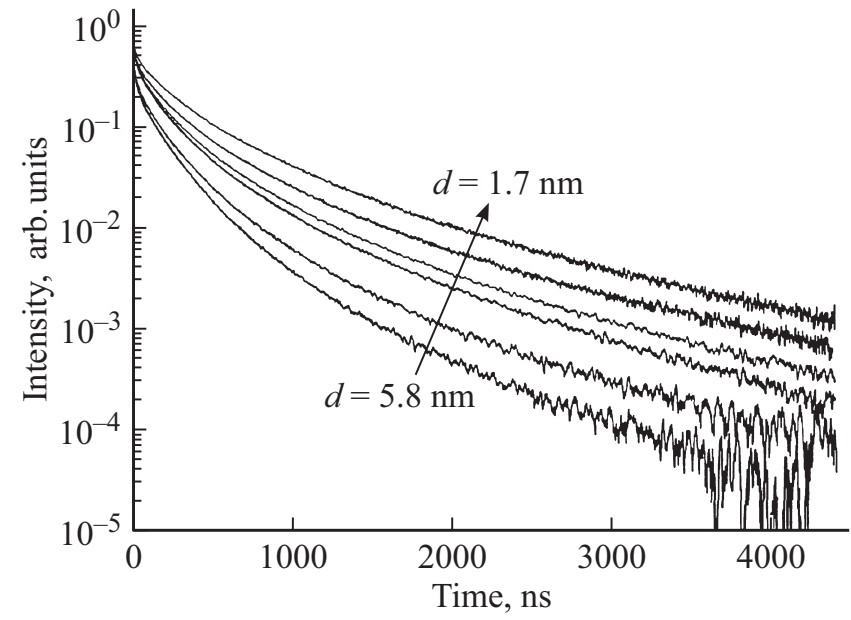

Pис. 7. Кинетика затухания люминесценции в максимуме полосы рекомбинационной люминесценции в коллоидных КТ $\mathrm{CdS} / \mathrm{TGA}$ со средними размерами $d=1.7,2.25,2.7,3.6,4.5$, 5.8 HM.

да фотолюминесценции также был найден несколькими авторами для широких спектров фотолюминесценции, связанных с рекомбинацией на ловушках [13,39-41].

Главной обнаруженной закономерностью является замедление затухания люминесценции с увеличением ее длины волны (уменьшением энергии кванта). В результате имеет место особая динамика нормированного мгновенного спектра свечения (см. вставку на рис. 6). По мере затухания свечения максимум полосы сдвигается в длинноволновую сторону. Мгновенные спектры свечения получены с привлечением данных стационарного спектра свечения и кривых затухания на каждой длине волны, измеренных при постоянной интенсивности импульсного возбуждения и времени накопления сигнала. Вторая важная особенность заключается в замедлении затухания люминесценции в максимуме спектров фотолюминесценции при увеличении размера КТ (рис. 7).

\section{4. Обсуждение полученных результатов}

Представленные экспериментальные результаты свидетельствуют о формировании КT CdS/TGA со средними размерами 1.7-5.8 нм. Формирующиеся коллоидные КТ представляют собой нанокристаллы $\mathrm{CdS}$ с кубической решеткой, что подтверждается данными рентгеновской дифрактометрии и спектроскопии ГКР.

Синтезированные коллоидные КТ проявляют размерный эффект в спектрах оптического поглощения и фотолюминесценции. Размерный эффект в фотолюминесценции проявляется в красном смещении максимума спектра люминесценции от 490 для наименьших КТ $(d=1.7 \mathrm{Hм})$ к 710 нм для наиболее крупных КТ $(d=5.8 \mathrm{HM})$.
Совокупность полученных экспериментальных данных также подтверждает донорно-акцепторный характер наблюдаемой в КT CdS/TGA рекомбинационной люминесценции. Основным доводом в пользу рекомбинации в донорно-акцепторных парах является длинноволновое смещение спектра люминесценции по мере затухания люминесценции. Энергия кванта рекомбинационной люминесценции на донорно-акцепторных парах определяется выражением $[42,43]$

$$
\hbar \omega=E_{g}-E_{d}-E_{a}+\frac{e^{2}}{\varepsilon\left|r_{d}-r_{a}\right|},
$$

где $E_{g}$ - ширина запрещенной зоны для массивного полупроводника или энергия экситона в поглощении для КТ, $E_{d}$ и $E_{a}-$ энергии связи донора и акцептора, $\varepsilon-$ диэлектрическая проницаемость, $r_{d}-r_{a}-$ расстояние между донором и акцептором. Выражение (1) предполагает, что пространственным распределением волновых функций можно пренебречь по сравнению с расстоянием между донором и акцептором. Знак перед кулоновским слагаемым определяется зарядом донора и акцептора до и после рекомбинации электрона и дырки. Как правило, донор и акцептор с захваченными носителями заряда являются нейтральными. После испускания фотона донор положительно заряжен, а акцептор отрицательно заряжен. Тогда из-за возникающего кулоновского взаимодействия уровни энергии донора и акцептора приближаются друг к другу на энергию кулоновского взаимодействия. В таком случае наибольшей энергией кванта люминесценции обладают переходы в донорно-акцепторных парах с наименьшими расстояниями между донором и акцептором. Для них вероятность рекомбинации выше. Согласно работе [42], вероятность рекомбинации в донорно-акцепторной паре определяется как

$$
W(r)=W_{0} \exp \left(-2 r / a_{\mathrm{B}}\right)
$$

где $W_{0}$ - не зависит от расстояния между донором и акцептором и определяется типом полупроводника [42], $a_{\mathrm{B}}-$ боровский радиус донора. Таким образом, близко расположенные донор и акцептор определяют свечение на начальном этапе затухания. По мере затухания люминесценции остаются невысвеченными наиболее удаленные донорно-акцепторные пары. Это приводит к длинноволновому смещению полосы люминесценции при затухании. Эти качественные рассуждения подтверждаются также данными, представленными на рис. 7 для KT CdS/TGA различного размера. Среднее расстояние между донором и акцептором тем больше, чем больше размер КТ. При увеличении среднего размера должно происходить замедление затухания люминесценции, что и наблюдали в эксперименте.

Заключение относительно механизма люминесценции для KT CdS/TGA согласуется с данными работ для КТ $\mathrm{CdS}$, пассивированных (3-меркаптопропил)триметоксисиланом, гексаметафосфатом натрия [13,15-17], в ко- 
торых на основании исследования температурной зависимости положения максимума и кинетики затухания люминесценции также сделано заключение о донорноакцепторном механизме рекомбинации [42]. При этом энергия связи донора менялась в пределах от 0.004 до 0.285 эВ при различных температурах [16]. Реализация наиболее объективного подхода в работе [12] также показала донорно-акцепорный механизм свечения. В ней исследовали тушение люминесценции в КТ CdS различными примесями (метилвиологен и нитрометан). На основании данных о затухании люминесценции и электрохимическом потенциале тушителей пришли к выводу, что центр люминесценции в КТ состоит из мелкой электронной ловушки и глубокой дырочной, а люминесценция возникает в результате рекомбинации на донорно-акцепторной паре.

Еще одной важной экспериментальной особенностью является незначительное смещение экситонного максимума в спектрах возбуждения люминесценции при сильном изменении длины волны регистрации свечения (пятикратное различие). Этот факт вступает в кажущееся противоречие с установленной размерной зависимостью полосы люминесценции, представленной на рис. 4. Действительно, при изменении размера КТ смещается как энергия экситона в поглощении, так и полоса люминесценции, причем эти сдвиги слабо различаются (стоксов сдвиг мало зависит от размера КТ). Однако в случае донорно-акцепторной рекомбинации в наблюдаемой полосе свечения из-за распределения доноров и акцепторов по расстояниям в КТ одного размера при их резонансном возбуждении полоса люминесценции будет значительно уширена. Тогда при регистрации люминесценции на определенной длине волны найдутся КT CdS различающихся размеров и с разноудаленными донором и акцептором, которые будут высвечиваться на одной длине волны и давать вклад в спектр возбуждения. Тогда зависимость от длины волны регистрации люминесценции будет нивелирована, что является вторым доводом в пользу донорно-акцепторного механизма возникающего в КT CdS/TGA свечения.

\section{5. Заключение}

В работе исследованы оптические свойства коллоидных KT CdS, пассивированных тиогликолевой кислотой, со средними размерами от 1.7 до 5.8 нм. Показано, что уменьшение среднего размера КТ в образце приводит не только к синему сдвигу полос поглощения, но и к аналогичному сдвигу рекомбинационной полосы, причем стоксов сдвиг несколько увеличивается, от 1 до 1.25 эВ. Обнаружено, что затухание люминесценции ускоряется при уменьшении длины волны регистрируемой люминесценции в пределах рекомбинационной полосы. Это приводит к длинноволновому смещению полосы свечения по мере затухания люминесценции, что указывает на донорно-акцепторный характер наблюдае- мой люминесценции. Обнаружено, что сдвиг спектров возбуждения, составляющий 0.2 эВ, при сканировании по полосе рекомбинационной люминесценции значительно меньше изменения длины волны регистрируемого свечения (1 эВ). На основании полученных экспериментальных данных сделано заключение о донорно-акцепторном характере излучательной рекомбинации в коллоидных квантовых точках $\mathrm{CdS}$, пассивированных тиогликолевой кислотой.

Работа выполнена при поддержке грантом РФФИ (Бел_мол_а № 17-52-04090) и БРФФИ (Ф17РМ-077).

\section{Список литературы}

[1] D. Bera, L. Qian, T.-K. Tseng, P.H. Holloway. Materials, 3, 2260 (2010).

[2] T. Pons, H. Mattoussi. An. Biomed. Engin., 37 (10), 1934 (2009).

[3] D.E. Prasuhn, A. Feltz, J.B. Blanco-Canosa, K. Susumu, M.H. Steawart, B.C. Mei, A.V. Yakovlev, Ch. Loukou, J. Mallet, M. Oheim, Ph.E. Dawson, I.L. Medintz. ACS Nano, 4, 5487 (2010).

[4] A.I. Ekimov, I.A. Kudryavtsev, M.G. Ivanov, Al.L. Efros. J. Luminesc., 46, 83 (1990).

[5] Sh. Tiwari, S. Tiwari. Cryst. Res. Technol., 41 (1), 78 (2006).

[6] J.R. Fernandez, M. de Souza-Parise, P.C. Morais. Surf. Sci., 601 (18), 3805 (2007).

[7] O.Ye. Rayevska, G.Ya. Grodzyuk, V.M. Dzhagan, O.L. Stroyuk, S.Ya. Kuchmiy, V.F. Plyusnin, V.P. Grivin, M.Ya. Valakh. J. Phys. Chem. C, 114 (51), 22478 (2010).

[8] A.V. Katsaba, S.A. Ambrozevich, A.G. Vitukhnovsky, V.V. Fedyanin, A.N. Lobanov, V.S. Krivobok, R.B. Vasiliev, I.G. Samatov. J. Appl. Phys., 113, 184306 (2013).

[9] M. Nirmal, D.J. Norris, M. Kuno, M.G. Bawendi, Al.L. Efros, M. Rosen. Phys. Rev. Lett., 75 (20), 3728 (1995).

[10] J. Li, J.-B. Xia. Phys. Rev. B, 62 (19), 12613 (2000).

[11] D. Kim, T. Mishima, K. Thomihira, M. Nakayama. J. Phys. Chem. C, 112 (29), 10668 (2008).

[12] A. Hasselbarth, A. Eychmuller, H. Weller. Chem. Phys. Lett., 203 (23), 271 (1993).

[13] N. Chestnoy, T.D. Harris, R. Hull, L.E. Brus. J. Phys. Chem., 90, 3393 (1986).

[14] Y. Wang, A. Suna, J.E.F. Hilinski, P.A. Lucas, R.D. Johnson. J. Chem. Phys., 92 (11), 6927 (1990).

[15] S.F. Wuister, A. Meijerink J. Luminesc., 102-103, 338 (2003).

[16] A. Eychmüller, A. Hässelbarth, L. Katsikas, H. Weller. J. Luminesc., 48-49, 745 (1991).

[17] M. O’Neil, J. Marohn, G. McLendon. J. Phys. Chem., 94, 4356 (1990).

[18] Y. Kobayashi, T. Nishimura, H. Yamaguchi, N. Tamai. J. Phys. Chem. Lett., 2, 1051 (2011).

[19] D.I. Chepic, A1.L. Efros, A.I. Ekimov, M.G. Ivanov, V.A. Kharchenko, L.A. Kudriavtsev, T.V. Yazeva. J. Luminesc., 47, 113 (1990).

[20] Y. Wang, N. Herron. Phys. Rev. B, 42 (11), 7253 (1990).

[21] A. Aboulaich, D. Billaud, M. Abyan, L. Balan, J.-J. Gaumet, G. Medjadhi, J. Ghanbaja, R. Schneider. ACS Appl. Mater. Interfaces, 4 (5), 2561 (2012).

[22] Y.-M. Mo, Y. Tang, F. Gao, J. Yang, Y.-M. Zhangn. Ind. Eng. Chem. Res., 51 (17), 5995 (2012). 
[23] S. Santhi, E. Bernstein, F. Paille. J. Luminesc., 117 (1), 101 (2006).

[24] D. Kim, T. Mishima, M. Nakayama. Physica E, 21 (24), 363 (2004).

[25] T. Vossmeyer, L. Katsikas, M. Giersig, I.G. Popovic, K. Diesner, A. Chemseddine, A. Eychmuller, H. Weller. J. Phys. Chem., 98 (31), 7665 (1994).

[26] N. Herron, Y. Wang, H. Eckert. J. Am. Chem. Soc., 112, 1322 (1990).

[27] P. Reiss, M. Protiere, L. Li. Small, 5 (2), 154 (2009).

[28] Н.Г. Пивен, Ю.Б. Халавка, Л.П. Щербак. Неорг. матер., 44 (10), 1174 (2008) [Inorg. Mater., 44 (10), 1047 (2008)].

[29] M. Tayebi, M.T. Yaraki, A. Mogharei, M. Ahmadieh, M. Tahriri, D. Vashaee, L. Tayebi. J. Fluoresc., 26, 1787 (2016).

[30] М.С. Смирнов, Д.И. Стаселько, О.В. Овчинников, А.Н. Латышев, О.В. Буганов, С.А. Тихомиров, А.С. Перепелица. Опт. и спектр., $115(5), 737$ (2013) [Optics Spectroscopy, $115(5), 651$ (2013)].

[31] О.В. Овчинников, М.С. Смирнов, Б.И. Шапиро, Т.С. Шатских, А.Н. Латышев, Pham Thi Hai Mien, В.Ю. Хохлов. Опт. и спектр., 115 (3), 389 (2013) [Optics Spectroscopy, 115 (3), 340 (2013)].

[32] N.V. Korolev, M.S. Smirnov, O.V. Ovchinnikov, T.S. Shatskikh. Physica E, 68, 159 (2015).

[33] O.V. Ovchinnikov, M.S. Smirnov, N.V. Korolev, P.A. Golovinski, A.G. Vitukhnovsky. J. Luminesc., 179, 413 (2016).

[34] M.S. Smirnov, O.V. Buganov, E.V. Shabunya-Klyachkovskaya, S.A. Tikhomirov, O.V. Ovchinnikov, A.G. Vitukhnovsky, A.S. Perepelitsa, A.S. Matsukovich, A.V. Katsaba. Physica E, 84, 511 (2016).

[35] А.Г. Милёхин, Л.Л. Свешникова, Т.А. Дуда, Н.В. Суровцев, С.В. Адищев, Д.Р.Т. Цан. Письма ЖЭТФ, $88(12), 918$ (2008).

[36] I. Honma, T. Sano, H. Komiyama. J. Phys. Chem., 97, 6692 (1993).

[37] W.W. Yu, L. Qu, W. Guo, X. Peng. Chem. Mater., 15, 2854 (2003).

[38] M. Majumder, S. Karan, B. Mallik. J. Luminesc., 131, 2792 (2011).

[39] L.E. Shea-Rohwer, J.E. Martin. J. Luminesc., 127, 499 (2007).

[40] D. Kim, M. Miyamoto, T. Mishima, M. Nakayama. J. Appl. Phys., 98, 083514 (2005).

[41] J.E. Martin, L.E. Shea-Rohwer. J. Luminesc., 121, 573 (2006).

[42] G.H. Döchler. Phys. Status Solidi B, 45, 705 (1971).

[43] X.S. Zhao, J. Schroeder, P.D. Persans, T.G. Bilodeau. Phys. Rev. B, 43, 12580 (1991).

Редактор Л.В. Шаронова

\section{The size-dependent optical properties of colloidal CdS quantum dots, passivated with thioglycolic acid}

\section{T.S. Kondratenko ${ }^{1}$, M.S. Smirnov ${ }^{1}$, O.V. Ovchinnikov ${ }^{1}$,} E.V. Shabunya-Klyachkovskaya ${ }^{2}$, A.S. Matsukovich², A.I. Zvyagin ${ }^{1}$, Y.A. Vinokur ${ }^{1}$

${ }^{1}$ Voronezh State University, 394018 Voronezh, Russia

${ }^{2}$ Stepanov Institute of Physics, National Academy of Sciences of Belarus, 220072 Minsk, Belarus

\begin{abstract}
The paper presents results of studying the optical properties of ensembles of colloidal CdS quantum dots, passivated with thioglycolic acid, with average dimensions from 1.7 to $5.8 \mathrm{~nm}$. $X$-ray diffractometry and Raman spectroscopy have shown that quantum dots were crystallize in a cubic crystal lattice. The regularities of the size effect in the spectra of optical absorption and luminescence, as well as in the luminescence excitation spectra, manifested in the blue shift of the corresponding bands with a decrease in the size of the quantum dots are established. Based on the analysis of nanosecond luminescence kinetics, a conclusion was made about the donor-acceptor mechanism of the observed radiative recombination.
\end{abstract}

